\title{
Analisis Perencanaan Pajak Penghasilan PPh 21 Sebagai Upaya untuk Meningkatkan Efesiensi Beban Pajak Studi Kasus Pada Persek MJH
}

\author{
Mohammad Affan Mantu ${ }^{1 *}$ Achmad Ibnu Sholeh ${ }^{2}$ \\ ${ }^{1,2}$ Institut Ilmu Sosial dan Managemen STIAMI, Jakarta, Indonesia \\ Email: ahmadibnu55@gmail.com
}

\section{ARTICLE INFO}

\section{Keywords}

Tax Planning, Gross Up,

Improving Tax Burden

Efficiency

\begin{abstract}
Tax planning is a process of organizing taxpayer's business in such a way that its payable tax, either income or other taxes, is in minimum amount. The company can save coporate income payment by means of applying Gross Up method in estimating income tax PPh 21 but the company applied gross method. This research aims to analyze the estimation of PPh 21 used by Persek Mjayahadi \& Co through the estimation of PPh 21 using Gross and Gross Up methods as well as constraints an attempts taken to save the corporate tax. The author used Chairl Anwar Pohan's (2017:21) theoy. The research method employed was descriptive quatitative one. Techniques of collecting data used were observation, interview, and documentation. The result of research shows that total tax assumed by the employees is IDR 2,431,591,608, but following the use of gross up method, it becomes IDR 2,429,661,781, with the difference of IDR 1,929,827. Therefore, the net profit after tax subtracted wtth nondeductible burden before the application of gross Up method Is IDR 7,987,666,865, and after the appIication of gross up is IDR 7,989,596,692. Therefore, there is a difference of IDR 1,929,827, meaning equal to the tax efficiency.
\end{abstract}

\section{PENDAHULUAN}

Sumber penerimaan negara yang utama adalah berasal dari Pajak, yang mana pajak akan menjadi pengurang dari laba bersih perusahaan maupun penghasilan wajib pajak orang pribdai. Setiap perusahaan yang telah memenuhi kriteria sebagai wajib pajak badan, baik itu adalah perusahaan dagang, perusahaan jasa, ataupun perusahan manufaktur tidak akan terlepas dari kewajibannya untuk membayar pajak. Dalam pelaksanaannya terdapat perbedaan kepentingan antara Wajib Pajak dengan pemerintah. Wajib Pajak memiliki kepentingan untuk membayar pajak sekecil-kecilnya karena dengan membayar pajak berarti mengurangi kemampuan ekonomis Wajib Pajak, sedangkan pemerintah memiliki kepentingan memerlukan dana untuk membiayai penyelenggaraan pemerintahan dengan sebesar-besarnya, karena sebagian besar penerimaan berasal dari pembayaran pajak. Adanya perbedaan kepentingan ini menyebabkan Wajib Pajak cenderung untuk mengurangi jumlah pembayaran pajak, baik secara legal maupun illegal.

Perbedaan ini dapat dilihat dari pada book tax difference, dimana apabila pajak tangguhan akuntansi lebih besar daripada pajak tangguhan fiskal maka perusahaan akan mendapat manfaat pajak tangguhan (deferred tax benefit) dan apabila pajak tangguhan akuntansi lebih kecil dari pajak tangguhan fiskal, maka perusahaan harus membayar beban pajak tangguhan (deferred tax expence). Oleh karena itu perusahaan harus meminimalisasikan jumlah pajak tangguhan fiskal, agar perusahaan memperoleh cadangan kas yang digunakan untuk meningkatkan laba perusahaan. Selain itu diharapkan manajemen mengetahui faktor-faktor yang akan dimanfaatkan untuk melakukan penghematan pajak, sehingga langkah yang dilakukan adalah mengimplementasikan secara formal dan material.

Upaya untuk mengefeisensikan pajak sering disebut dengan teknik perencanaan pajak (tax planning) Perencanaan pajak merupakan langkah awal dalam manajemen pajak. Manajemen pajak merupakan sarana untuk memenuhi kewajiban perpajakan dengan benar tetapi jumlah pajak yang dibayar dapat ditekan serendah mungkin untuk memperoleh laba dan likuiditas yang diharapkan .

Pajak penghasilan PPh 21 dari daftar gaji karyawan Persek Mjayahadi pada tahun 2017 yaitu sebesar Rp 36.008.510 sehingga Presentase Pajak Penghasilan PPh Pasal 21 dengan menggunakan Metode Gross yaitu Sebesar 3,66 \% dari daftar gaji karyawan sebesar Rp 982.385.177, dan pada tahun 2018 yaitu sebesar Rp 21.694.300 sehingga Presentase Pajak Penghasilan PPh Pasal 21 dengan Menggunakan Metode Gross 
yaitu Sebesar 3,10 \% dari daftar gaji karyawan sebesar Rp 697.634.390 .Pada tahun 2017 dengan Menggunakan Metode Gross Up presentase pajak penghasilan PPh Pasal 21 yaitu sebesar 3,99\% ,dan pada tahun 2018 dengan menggunakan metode Gross Up Pajak penghasilan PPh Pasal 21 yaitu sebesar 3,33\% (Sumber : Data Internal Persek Mjayahadi \& Co tahun 2017-2018, diolah Oleh Penulis).

Pada tahun 2017 Persek MjayaHadi menggunakan tarif pasal 31 E UU Pajak penghasilan dikarenakan omset pada saat itu sebesar Rp 13.390.014.999 sehingga pajak penghasilan terutang pada tahun 2017 yakni sebesar Rp 1.769.222.578. Sehingga persentase net profit terhadap Omset yakni sebesar $22 \%$ sedangkan persantase pph Badan terhadap Omset adalah sebesar $13 \%$, dan pada tahun 2018 omset pada saat itu sebesar Rp 24,310,850,000 sehingga pajak penghasilan terutang pada tahun 2018 yakni sebesar Rp 2,413,042,358 Sehingga persantase net profit terhadap Omset yakni sebesar $23 \%$ sedangkan persantase pph Badan terhadap Omset adalah sebesar 10 \% (Sumber : Data Internal Persek Mjayahadi \& Co tahun 2017-2018, diolah Oleh Penulis).

Namun demikian penulis temukan pada wawancara pra penelitian dengan informan dari perusahaan ini yaitu seharusnya perusahaan bisa melakukan penghematan pembayaran pajak penghasilan badan dengan cara menerapkan Gross Up method dalam perhitungan pajak penghasilan PPh 21 atas gaji karyawan namun yang diterapkan oleh perusahaan adalah Gross Method mengakibatkan karyawan terbebani dengan beban $\mathrm{PPh}$ Pasal 21. Sedangkan dengan mengunakan Gross Up method memberikan keuntungan bagi perusahaan karena PPh Badannya semakin rendah, dan karyawan tidak terbebani deng an PPh 21.

Tujuan dari masalah yang ingin dibahas dalam penulisan ini adalah untuk menganalisis pelaksanaan perencanaan pajak penghasilan PPh 21 dalam upaya meningkatkan efesiensi Beban Pajak pada Persek Mjayhadi \& Co Tahun 2018, dampak perubahan yang diperoleh dengan dilakukannya strategi Metode Gross up PPh 21 yang di tetapkan pada Persek Mjayhadi \& Co Tahun 2018 serta hambatan dan upaya yang perlu dilakukan dalam pelaksanaan Perencanaan pajak untuk meningkatkan efesiensi beban pajak pada Persek Mjayhadi \& Co Tahun 2018

\section{KAJIAN LITERATUR}

Menurut Mansury (1996:23), Administrasi perpajakan mempunyai tiga pengertian yaitu:

1) Suatu instansi atau badan yang mempunyai wewenang dan tanggung jawab untuk menyelenggarakan pungutan pajak,

2) Orang-orang yang terdiri dari pejabat dan pegawai yang bekerja pada instansi perpajakan yang secara nyata melaksanakan kegiatan pemungutan pajak.

3) Kegiatan penyelenggaraan pungutan pajak oleh suatu instansi atau badan yang ditatalaksanakan sedemikian rupa sehingga dapat mencapai sasaran yang telah digariskan dalam kebijaksanaan perpajakan, berdasarkan sarana hukum yang ditentukan oleh undang-undang perpajakan secara efisien.

Sedangkan menurut Soemitro dalam Mardiasmo (2013:1) mengatakan pajak sebagai berikut : "Pajak adalah iuran rakyat kepada kas negara berdasarkan undangundang (yang dapat dilaksanakan) dengan tiada mendapat jasa timbal (kontraprestasi) yang langsung dapat ditunjukkan dan yang digunakan untuk membayar pengeluaran umum."

Menurut Pohan (2017: 18) "Perencanaan pajak adalah proses mengorganisasi usaha wajib pajak orang pribadi maupun badan usaha sedemikian rupa dengan memamnfaatkan bebbagai celah kemungkinan yang dapat ditempuh oleh perusahaan dalam koridor ketentuan peraturan perpajakan ( loopholes), agar perusahaan dapat membayar pajak dalam jumlah minimum."

Menurut Pohan ( 2017: 20 ), ada beberapa manfaat yang bisa diperoleh dari perencanaan pajak yang dilakukan secara cermat, yaitu:

1) Penghematan kas keluar, karena beban pajak yang merupakan unsur biaya dapat dikurangi

2) Mengatur aliran kas masuk dan keluar (cash flow ), karena dengan perencanaan pajak yang matang dapat diperkirakan kebutuhan kas untuk pajak, dan menentukan saat pembayaran sehingga perusahaan dapat menyusun anggaran kas secara lebih akurat

Menurut Pohan (2017: 21), menyatakan ada tiga persyaratan perencanaan pajak yang baik, yaitu:

1) Tidak melanggar ketentuan Perpajakan, jika rekayasa Perpajakannya yang didesain dan diimplementasikan bukan merupakan tax evasion. 
2) Secara bisnis masuk akal, kewajaran melakukan transaksi bisnis harus berpegang kepada praktik perdagangan yang sehat dan menggunakan standard arn's length price, atau harga pasar yang wajar, yakni tingkat harga antara pembeli dan penjual yang independen, bebas melakukan transaksi.

3) Didukung oleh bukti- bukti yang memadai, (Misalnya, kontrak, invoice, faktur pajak, PO dan DO ). Kebenaran formal dan materill suatu transaksi keuangan perusahaan dapat dibuktikan dengan adanya kontrak perjanjian dengan pihak ketiga atau purchase order dari pelanggan, bukti penyerahan barang atau jasa (Delivery order ), invoice, faktur pajak sebagai bukti penagihannya serta pembukuannya (General ledger ).

Dalam Undang-Undang PPh 1984 pasal 4 ayat (1) dijelaskan bahwa penghasilan adalah setiap tambahan kemampuan ekonomis yang diterima atau diperoleh Wajib Pajak, baik yang berasal dari Indonesia maupun dari luar Indonesia, yang dapat dipakai untuk konsumsi atau untuk menambah kekayaan Wajib Pajak yang bersangkutan, dengan nama dan dalam bentuk apa pun.

Menurut Mardiasmo (2016: 197 ) "PPh pasal 21 adalah pajak atas penghasilan berupa gaji, upah, honorarium, tunjangan, dan pembayaran lain dengan nama dan dalam bentuk apa pun sehubungan dengan pekerjaan atau jabatan, jasa dan kegiatan yang dilakukan oleh orang pribadi subjek pajak dalam negeri."

Menurut Pohan (2017:76), menyatakan ada tiga metode pemotongan PPh Pasal 21 yang dapat dipilih oleh Wajib Pajak yaitu :

1. Gross Method/ ditanggung oleh karyawan merupakan metode pemotongan pajak yang jumlah penghasilan terutangnya akan ditanggung oleh karyawan itu sendiri, sehingga benar-benar mengurangi penghasilan. Istilah yang sering digunakan adalah bahwa PPh Pasal 21 dipotong oleh perusahaan.

2. Net Method / ditanggung oleh perusahaan merupakan metode pemotongan pajak yang jumlah penghasilan terutangnya akan ditanggung oleh perusahaan yang bersangkutan. Dengan demikian, gaji yang diterima oleh karyawan tersebut tidak dikurangi dengan PPh Pasal 21 karena perusahaanlah yang menanggung biaya/ beban PPh pasal 21. PPh Pasal 21 yang ditanggung perusahaan tersebut tidak boleh dikurangkan dari penghasilan bruto perusahaan, karena tidak dimasukkan sebagai faktor penambahan pendapatan dalam SPT PPh Pasal 21.

3. Gross Up Method / ditunjang merupakan metode pemotongan pajak dimana perusahaan memberikan $\mathrm{PPh}$ Pasal 21 dalam bentuk tunjangan, maka jumlah tunjangan tersebut akan menambah penghasilan karyawan dan dikenai PPh Pasal 21. Dalam hal ini penghitungan PPh dilakukan dengan cara gross up dimana besar tunjangan pajak sama dengan jumlah PPh Pasal 21 terutang masing-masing karyawan.

Rumus gross up mengalami penyesuaian tarif pajak, biaya jabatan, dan PTKP nya juga berubah

Tabel 1 Rumus Tunjangan Pajak dengan Metode Gross $U p$

\begin{tabular}{|l|l|}
\hline Lapisan 1 & $\begin{array}{l}\text { PKP Rp0 s/d Rp. 50.000.000 } \\
\text { Pajak = 1/0,95 \{PKP X 5 \% }\}\end{array}$ \\
\hline Lapisan 2 & $\begin{array}{l}\text { PKP di atas Rp. 50.000.000 s/d Rp. 250.000.000 } \\
\text { Pajak= 1/0,85 }\{(\text { PKP X 15 \% )- 5 juta }\}\end{array}$ \\
\hline Lapisan 3 & $\begin{array}{l}\text { PKP di atas Rp. 250.000.000 s/d Rp. 500.000.000 } \\
\text { Pajak=1/0,75 }\{(\text { PKP X 25 \% )- } 30 \text { juta }\}\end{array}$ \\
\hline Lapisan 4 & $\begin{array}{l}\text { PKP di atas Rp. 500.000.000 } \\
\text { Pajak=1/0,70 }\{\text { (PKP X 35 \% )- 55 juta }\}\end{array}$ \\
\hline
\end{tabular}

Sumber : Pohan (2017: 108)

Tarif pajak penghasilan pribadi perhitungannya dengan menggunakan tarif progresif

Tabel 2 Tarif Pajak Pph 21

\begin{tabular}{|l|l|}
\hline Lapisan Penghasilan Kena Pajak & Tarif Pajak \\
\hline Sampai dengan Rp 50.000.000 & $5 \%$ \\
Diatas Rp 50.000.000 - Rp 250.000.000 & $15 \%$ \\
Diatas Rp 250.000.000 - Rp 500.000.000 & $25 \%$ \\
Diatas Rp 500.000.000 & $30 \%$ \\
& \\
\hline
\end{tabular}

Sumber : Menurut Pohan (2017: 59) 

pribadi

PTKP adalah besarnya penghasilan yang menjadi batasan tidak kena pajak bagi wajib pajak orang

Tabel 3 PTKP

\begin{tabular}{|l|r|}
\hline \multicolumn{1}{|c|}{ STATUS } & PTKP 2016 (baru) \\
\hline TK (Tidak Kawin) & $54,000,000$ \\
\hline $\mathrm{K} / 0$ (kawin tanpa tanggungan) & $58,500,000$ \\
\hline $\mathrm{K} / 1$ (Kawin dengan satu tanggungan) & $63,000,000$ \\
\hline $\mathrm{K} / 2$ (kawin dengan dua tanggungan) & $67,500,000$ \\
\hline $\mathrm{K} / 3$ (kawin dengan tiga tanggungan) & $72,000,000$ \\
\hline
\end{tabular}

Sumber : Resmi (2017: 191)

Menurut Nordiawan (2014) Efisiensi Pajak Penghasilan adalah "Suatu organisasi, program, atau hal hal semacamnya dikatakan efisien apabila bisa menghasilkan output tertentu dengan input yang paling rendah, atau dengan input tertentu mampu menghasilkan output sebesar-besarnya".

Kerangka konseptual dalam penelitian ini untuk melihat perencanaan pajak (Tax Plannning) Pph 21 yang dapat diukur dengan membandingkan antara Metode Gross, Metode Net dan Metode Gross Up ditentukan dari hasil yang telah ditetapkan. Dari sisi perusahaan atau wajib pajak, jika pajak yang dibayar lebih besar dari jumlah yang semestinya, akan mengakibatkan kerugian sedangkan dari sisi pemerintah pemerintah, jika pajak yang dibayar oleh wajib pajak lebih kecil dari yang seharusnya mereka bayarkan , maka pendapatan negara dari sektor pajak yang akan berkurang. Upaya yang bisa dilakukan oleh pengusaha atau wajib pajak yaitu dengan meminimalkan beban pajak dalam batas yang tidak melanggar aturan, karena pajak merupakan salah satu faktor pengurang laba. Semakin besar penghasilan, maka semakin besar pula pajak terutangnya. Perencanaan pajak atau Tax Planning diukur dari 3 indikator yaitu, Secara bisnis masuk akal (reasonable), Perencanaan pajak yang tidak melanggar ketentuan perpajakan ( Tax Avoidance) dan Didukung oleh bukti - bukti pendukung yang memadai. Tujuan yang dimaksud dalam penelitian ini adalah untuk mengefisiensi kan beban pajak pada perusahaan Persek Mjayahadi\&CO Tahun 2018 .

\section{Gambar 2 Model Konseptual}

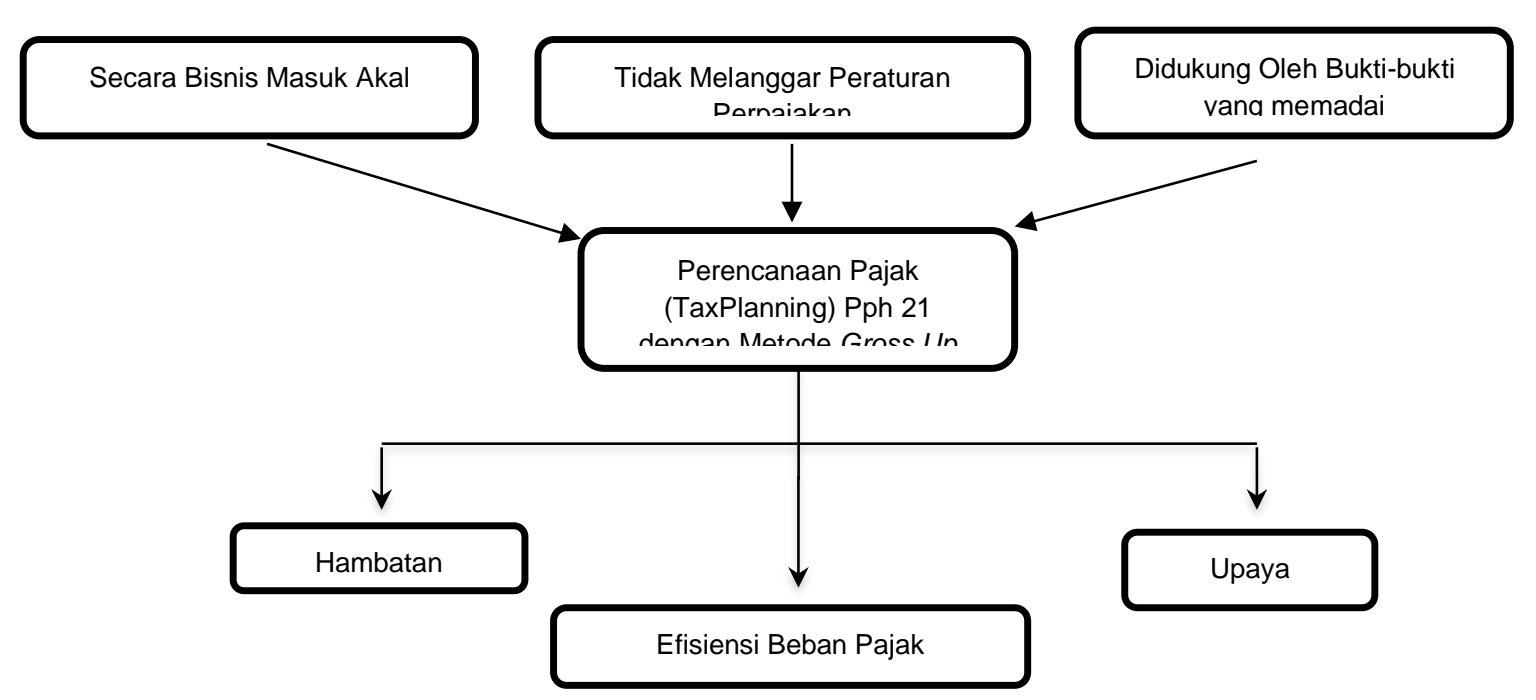

Sumber: Perencanaan pajak menurut Pohan (2017:21) yang diolah oleh Penulis 2020

\section{METODE PENELITIAN}

Metode penelitian yang digunakan dalam penelitian ini adalah metode penelitian kualitatif deskriptif. Jenis penelitian berdasarkan tujuan yang digunakan peneliti adalah penelitian deskriptif. Penelitian deskriptif menurut Nazir (2011:63) mengemukakan bahwa Metode deskriptif adalah suatu metode dalam meneliti status sekelompok manusia, suatu objek, suatu set kondisi, suatu sistem pemikiran, ataupun suatu kelas peristiwa pada masa sekarang. Tujuan penelitian deksriptif adalah untuk membuat deskripsi, gambaran atau 
lukisan secara sistematis, faktual dan akurat mengenai fakta-fakta, sifat- sifat serta hubungan antar fenomena yang diselidiki.

Sumber data dalam penelitian ini adalah data primer, data primer yang digunakan ialah wawancara dengan salah satu pihak di Persek Mjayahadi dan data sekunder yang secara tidak langsung diambil oleh peneliti berupa data Daftar Gaji Karyawan Tetap Persek Mjayahadi\&CO Tahun 2018.

Operasionalisasi konsep yang digunakan dalam penelitian ini memfokuskan permasalahan pada tahun 2018 yang terdiri dari Perencanaan pajak yang tidak melanggar ketentuan perpajakan, Secara bisnis masuk akal, Didukung oleh bukti - bukti yang memadai. Perhitungan PPh Pasal 21 diantaranya yaitu, Metode Gross, Metode Net, Metode Gross Up serta Efesiensi /penghematan Beban Pajak

Teknik pengumpulan data dalam penelitian ini menggunakan beberapa teknik yang diperlukan mengenai objek yang akan diteliti yaitu dengan wawancara, dokumentasi dan observasi.

Dalam penelitian ini teknik analisis data yang digunakan berupa Pengumpulan data, Reduksi Data, Penyajian data dan Penarikan Kesimpulan.

\section{HASIL DAN PEMBAHASAN}

Analisis penelitian ini berkaitan dengan perencanaan pajak penghasilan pph 21 sebagai upaya untuk meningkatkan efesiensi beban pajak pada Persek Mjayahadi \& Co Tahun 2018. Penelitian ini menggunakan teori menurut Pohan (2017: 21) yang mempunyai 3 indikator yaitu pajak yang tidak melanggar ketentuan perpajakan, Secara bisnis masuk akal, Didukung oleh bukti - bukti yang memadai. Perencanaan pajak adalah proses mengorganisasi usaha wajib pajak orang pribadi maupun badan usaha sedemikian rupa dengan memamnfaatkan berbagai celah kemungkinan yang dapat ditempuh oleh perusahaan dalam koridor ketentuan peraturan perpajakan ( loopholes), agar perusahaan dapat membayar pajak dalam jumlah minimum."

\section{Tabel IV.I Daftar Gaji Karyawan Tetap Persek Mjayahadi \& Co Tahun 2018(Rp)}

\begin{tabular}{|c|l|c|r|r|r|r|}
\hline \multicolumn{7}{|c|}{ Daftar Gaji Kary awan Tetap Persek MJAYAHADI \& Co Tahun 2018} \\
\hline No & $\begin{array}{c}\text { Nama } \\
\text { Karyawan }\end{array}$ & Status & Gaji Pokok & $\begin{array}{c}\text { Tunjangan } \\
\text { lainnya }\end{array}$ & $\begin{array}{c}\text { Tantiem, } \\
\text { Bonus, }\end{array}$ & $\begin{array}{c}\text { penghasilan } \\
\text { Bruto Setahun }\end{array}$ \\
\hline 1 & Tn.Si & TK/0 & 44.000 .000 & 2.274 .684 & - & 46.274 .684 \\
\hline 2 & Tn.wn & TK/0 & 72.000 .000 & 2.274 .684 & 3.500 .000 & 77.774 .684 \\
\hline 3 & Ny.ap & TK/0 & 72.000 .000 & 2.274 .684 & 3.500 .000 & 77.774 .684 \\
\hline 4 & tn.an & TK/0 & 72.000 .000 & 2.274 .684 & 3.500 .000 & 77.774 .684 \\
\hline 5 & Ny.mi & TK/0 & 119.000 .000 & 8.110 .210 & 70.000 .000 & 197.110 .210 \\
\hline 6 & Ny,dn & TK/0 & 24.000 .000 & 251.967 & - & 24.251 .967 \\
\hline 7 & Tn.ar & TK/0 & 14.000 .000 & - & - & 14.000 .000 \\
\hline 8 & Tn.md & K/2 & 14.000 .000 & - & - & 14.000 .000 \\
\hline 9 & Tn.yf & K/1 & 14.000 .000 & - & - & 14.000 .000 \\
\hline 10 & Tn.sy & TK/0 & 14.000 .000 & - & - & 14.000 .000 \\
\hline 11 & Tn.kih & TK/0 & 19.661 .722 & 311.755 & - & 19.973 .477 \\
\hline & Total & & $\mathbf{4 7 8 . 6 6 1 . 7 2 2}$ & $\mathbf{1 7 . 7 7 2 . 6 6 8}$ & $\mathbf{8 0 . 5 0 0 . 0 0 0}$ & $\mathbf{5 7 6 . 9 3 4 . 3 9 0}$ \\
\hline
\end{tabular}

Sumber: Data Internal Mjayahadi \& Co Tahun 2018 ( Diolah oleh penulis)

Berdasarkan tabel di atas yang bersumber dari Data Internal Mjayahadi \& Co Tahun 2018 dan diolah penulis dapat diketahui bahwa data penghasilan karyawan tetap Mjayahadi \&Co pada akhir tahun 2018 yang berjumlah 11 karyawan tetap. Dari data tersebut dapat diperoleh penghasilan bruto sebesar Rp.576.934.390,dari Gaji pokok ditambah THR dan Tunjangan Lainnya Dibawah ini merupakan hasil perhitungan PPh Pasal 21 Tahun 2018 pada Persek Mjayahadi \& Co yang telah penulis olah dengan menggunakan 3 alternative yang dapat digunakan oleh Persek Mjayahadi \& Co dalam upaya perencanaan pajak penghasilan Pasal 21 yaitu alternative pertama dengan pajak penghasilan metode gross yang ditanggung oleh karyawan, Alternative kedua dengan metode Net yang ditanggung oleh perusahaan dan alternative ketiga dengan menggunakan metode gross up.

\section{Ph Pasal 21 Ditanggung karyawan (Gross Method)}

PPh Pasal 21 ditanggung karyawan adalah metode yang saat ini digunakan oleh Persek Mjayahadi \& Co 2018 dalam menghitung pajaknya. Pada penggunaan metode ini, karyawan menanggung sendiri pajak terutang atas penghasilan yang diperolehnya. Berikut ini adalah perhitungan PPh Pasal 21 atas karyawan 
tetap Persek Mjayahadi \& Co 2018 dengan menggunakan metode gross method perhitungan pajak ditanggung karyawan sebagai berikut:

Tabel IV.2 Perhitungan PPh 21 Persek Mjayahadi \& Co Tahun 2018 Metode Gross (ditanggung Oleh karyawan)

\begin{tabular}{|c|c|c|c|c|c|c|c|c|c|c|c|c|}
\hline No & $\begin{array}{c}\text { Nama } \\
\text { Karyaw } \\
\text { an }\end{array}$ & PTKP & Gaji Pokok & $\begin{array}{l}\text { Tunjangan } \\
\text { lain lain }\end{array}$ & \begin{tabular}{|c|} 
Tantiem, \\
Bonus, \\
GratifikTHR \\
yang sifatnya \\
tidak tetap \\
\end{tabular} & $\begin{array}{l}\text { Ph. Bruto } \\
\text { Setahun }\end{array}$ & Biaya jabatan & $\begin{array}{l}\text { Ph.netto } \\
\text { Setahun }\end{array}$ & PTKP & PKP & $\begin{array}{c}\text { PPh21 } \\
\text { sebelum di } \\
\text { Gross Up }\end{array}$ & Pph 21 Setelah di Gross Up \\
\hline 1 & Tn.si & TK/0 & 44.000 .000 & 2.274 .684 & & 46.274 .684 & 2.313 .734 & 43.960 .950 & 54.000 .000 & - & - & - \\
\hline 2 & Tn.wn & TK/0 & 72.000 .000 & 2.274 .684 & 3.500 .000 & 77.774 .684 & 3.888 .734 & 73.885 .950 & 54.000 .000 & 19.885 .000 & 994.250 & 1.046 .579 \\
\hline 3 & Ny.ap & TK/0 & 72.000 .000 & 2.274 .684 & 3.500 .000 & 77.774 .684 & 3.888 .734 & 73.885 .950 & 54.000 .000 & 19.885 .000 & 994.250 & 1.046 .579 \\
\hline 4 & Tn.an & TK/0 & 72.000 .000 & 2.274 .684 & 3.500 .000 & 77.774 .684 & 3.888 .734 & 73.885 .950 & 54.000 .000 & 19.885 .000 & 994.250 & 1.046 .579 \\
\hline 5 & Ny.mi & TK/0 & 119.000 .000 & 8.110 .210 & 70.000 .000 & 197.110 .210 & 6.000 .000 & 191.110.210 & 54.000 .000 & 137.110 .000 & 15.566 .500 & 18.313 .529 \\
\hline 6 & Ny.dn & TK/0 & $24 . .000 .000$ & 251.967 & - & 24.251 .967 & 1.212 .598 & 23.039 .368 & 54.000 .000 & - & - & - \\
\hline 7 & Tn.ar & $K / 2$ & 14.000 .000 & & - & 14.000 .000 & 700.000 & 13.300 .000 & 54.000 .000 & - & - & - \\
\hline 8 & Tn.md & $\mathrm{K} / 1$ & 14.000 .000 & & - & 14.000 .000 & 700.000 & 13.300 .000 & 67.500 .000 & - & - & - \\
\hline 9 & Tn.yf & TK/0 & 14.000 .000 & & - & 14.000 .000 & 700.000 & 13.300 .000 & 63.000 .000 & - & - & - \\
\hline 10 & Tn.sy & TK/0 & 14.000 .000 & & - & 14.000 .000 & 700.000 & 13.300 .000 & 54.000 .000 & - & - & - \\
\hline 11 & Tn,kih & TK/0 & 19.661 .722 & 311.755 & - & 19.973 .477 & 998.674 & 18.974 .803 & 54.000 .000 & - & - & - \\
\hline \multicolumn{3}{|c|}{ Total } & 478.661 .722 & 17.772 .668 & 80.500 .000 & 576.934 .390 & 24.991.209 & 551.943 .181 & 616.500 .000 & 196.765 .000 & 18.549 .250 & 21.453 .268 \\
\hline
\end{tabular}

Sumber: Data Internal Mjayahadi \& co Tahun 2018( diolah oleh penulis 2020.

Berdasarkan tabel diatas perhitungan PPh 21 dari 11 karyawan tetap dengan menggunakan gross method (ditanggung oleh karyawan ) dapat diperoleh pajak penghasilan bruto setahun adalah setelah ditambahkan Tunjangan lain-lainya dan Tantiem THR,Grafitikasi sebesar Rp576.934.390 ,- setelah itu dikurangkan dengan biaya jabatan akan mendapatkan penghasilan Netto setahun sebesar Rp.551.943.181,-Penghasilan Netto setahun ini harus dikurangi dengan PTKP ( Penghasilan Tidak Kena Pajak ) sesuai dengan status dari masing-masing pegawai untuk mendapatkan penghasilan kena pajak (PKP ). PKP ini merupakan Dasar Pengenaan Pajak ( DPP ) yang dikalikan dengan Tarif Umum Progresif Pasal 17 UU Pajak Penghasilan No. 36 Tahun 2008 untuk mendapatkan PPh Pasal 21 terutang. PPh Pasal 21 terutang sebesar Rp. 18.549.250 yang langsung dipotong dari gaji karyawan tetap.

\section{PPh Pasal 21 ditanggung Perusahaaan (Net Method)}

$\mathrm{PPh}$ Pasal 21 ditanggung oleh perusahaan adalah salah satu metode pemotongan dalam perhitungan $\mathrm{PPh}$ 21 dimana perusahaan tersebut menanggung pajak atas karyawannya. Gaji yang diterima oleh karyawan tersebut tidak dikurangi dengan pph 21. Berikut ini adalah perhitungan PPh Pasal 21 atas karyawan tetap Persek Mjayahadi \& Co 2018 dengan menggunakan Net method perhitungan pajak ditanggung Perusahaan sebagai berikut :

\section{Tabel IV.3 Perhitungan PPh 21 Persek Mjayahadi \& Co Tahun 2018 Metode Net ( Ditanggung Perusahaan)}

\begin{tabular}{|c|c|c|c|c|c|c|c|c|c|c|c|c|}
\hline No & $\begin{array}{c}\text { Nama } \\
\text { Karya } \\
\text { wan }\end{array}$ & PTKP & Gaji Pokok & $\begin{array}{l}\text { Tunjangan } \\
\text { lain lain }\end{array}$ & $\begin{array}{c}\text { Tantiem, } \\
\text { Bonus, } \\
\text { GratifikTHR } \\
\text { yang sifatnya } \\
\text { tidak tetap } \\
\end{array}$ & $\begin{array}{l}\text { Ph. Bruto } \\
\text { Setahun }\end{array}$ & Biaya jabatan & $\begin{array}{l}\text { Ph.netto } \\
\text { Setahun }\end{array}$ & PTKP & PKP & $\begin{array}{c}\text { PPh21 } \\
\text { sebelum di } \\
\text { Gross Up }\end{array}$ & PPh 21 Setelah di Gross Up \\
\hline 1 & Tn.si & TK/O & 44.000 .000 & 2.274 .684 & & 46.274 .684 & 2.313 .734 & 43.960 .950 & 54.000 .000 & - & - & - \\
\hline 2 & Tn.wn & TK/O & 72.000 .000 & 2.274 .684 & 3.500 .000 & 77.774 .684 & 3.888 .734 & 73.885 .950 & 54.000 .000 & 19.885 .000 & 994.250 & 1.046 .579 \\
\hline 3 & Ny.ap & TK/O & 72.000 .000 & 2.274 .684 & 3.500 .000 & 77.774 .684 & 3.888 .734 & 73.885 .950 & 54.000 .000 & 19.885 .000 & 994.250 & 1.046 .579 \\
\hline 4 & Tn.an & TK/O & 72.000 .000 & 2.274 .684 & 3.500 .000 & 77.774 .684 & 3.888 .734 & 73.885 .950 & 54.000 .000 & 19.885 .000 & 994.250 & 1.046 .579 \\
\hline 5 & Ny.mi & TK/O & 119.000 .000 & 8.110 .210 & 70.000 .000 & 197.110 .210 & 6.000 .000 & 191.110 .210 & 54.000 .000 & 137.110 .000 & 15.566 .500 & 18.313 .529 \\
\hline 6 & Ny.dn & TK/O & $24 . .000 .000$ & 251.967 & - & 24.251 .967 & 1.212 .598 & 23.039 .368 & 54.000 .000 & - & - & - \\
\hline 7 & Tn.ar & $\mathrm{K} / 2$ & 14.000 .000 & & - & 14.000 .000 & 700.000 & 13.300 .000 & 54.000 .000 & - & - & - \\
\hline 8 & Tn.md & $\mathrm{K} / 1$ & 14.000 .000 & & - & 14.000 .000 & 700.000 & 13.300 .000 & 67.500 .000 & - & - & - \\
\hline 9 & Tn.yf & TK/O & 14.000 .000 & & - & 14.000 .000 & 700.000 & 13.300 .000 & 63.000 .000 & - & - & - \\
\hline 10 & Tn.sy & TK/O & 14.000 .000 & & - & 14.000 .000 & 700.000 & 13.300 .000 & 54.000 .000 & - & - & - \\
\hline \multirow[t]{2}{*}{11} & Tn, kih & TK/O & 19.661 .722 & 311.755 & - & 19.973 .477 & 998.674 & 18.974 .803 & 54.000 .000 & - & - & - \\
\hline & \multicolumn{2}{|c|}{ Total } & 478.661 .722 & 17.772 .668 & 80.500 .000 & 576.934 .390 & 24.991.209 & 551.943.181 & 616.500 .000 & 196.765 .000 & 18.549 .250 & 21.453 .268 \\
\hline
\end{tabular}

Sumber : Data Internal Mjayahadi \& Co Tahun 2018 ( Diolah oleh penulis) 
Dapat dilihat perhitungan PPh 21 dari 11 karyawan tetap menggunakan metode net method dapat diperoleh pajak penghasilan bruto setahun adalah setelah ditambahkan THR dan Tunjangan Lainnya sebesar Rp 576.934.390,- setelah itu dikurangkan dengan biaya jabatan akan mendapatkan penghasilan Netto setahun sebesar Rp.551.943.181,-. Penghasilan Netto setahun ini harus dikurangi Penghasilan Tidak Kena Pajak yang sesuai dengan status dari masing-masing karyawan untuk mendapatkan penghasilan kena pajak (PKP).

PKP ini merupakan Dasar Pengenaan Pajak ( DPP ) yang dikalikan dengan Tarif Umum Progresif Pasal 17 UU Pajak Penghasilan No. 36 Tahun 2008 untuk mendapatkan PPh Pasal 21 terutang. PPh Pasal 21 terutang sebesar Rp. 18.549.250 yang akan ditanggung oleh perusahaan. Dari sisi pegawai , Gaji yang diterima pegawai tersebut tidak dikurangi dengan $\mathrm{PPh} 21$ karena perusahaan yang menangung beban pph pasal 21 . Karena jumlah $\mathrm{PPh}$ pasal 21 yang ditanggung perusahaan tidak dimasukkan dalam perhitungan SPT PPh pasal 21, Sehingga tidak boleh dikurangkan dari penghasilan bruto perusahaan sebagai biaya deductible, dan perusahaan sebagai pemotong pajak wajib untuk membayar dan melaporkan ke kantor pajak.

\section{PPh pasal 21 ditunjang oleh perusahaan (Gross Up Method)}

Metode pemotongan pajak penghasilan pasal 21 dengan menggunakan Gross Up yang ditunjang oleh perusahaan, yaitu perusahaan memberikan tunjangan pada jumlah sama besar dengan jumlah pajak yang akan dipotong dari penghasilan karyawan. Perhitungan pajak tersebut menggunakan rumus tersendiri untuk menyamakan jumlah pajak yang akan dibayarkan dengan tunjangan pajak yang akan diberikan perusahaan terhadap karyawan. Bagi karyawan penerima tunjangan, tunjangan tersebut merupakan penghasilan, dan bagi perusahaan terkait tunjangan pajak tersebut boleh dijadikan pengurangan dalam menghitung besarnya pajak terutang perusahaan. Atau dengan kata lain tunjangan tersebut bisa dijadikan biaya oleh perusahaan

Rumus yang digunakan dalam menghitung besarnya tunjangan pajak dengan menggunakan metode gross up method disesuaikan dengan undang-undang pajak penghasilan No.36 Tahun 2008. Berikut ini perhitungan PPh Pasal 21 dengan menggunakan metode gross up sebagai berikut:

\section{Tabel IV. 4 Perhitungan PPh 21 Mjayahadi \& Co tahun 2018 Metode Gross Up ( Ditunjang Oleh Perusahaan)}

\begin{tabular}{|c|c|c|c|c|c|c|c|c|c|c|c|c|}
\hline No & $\begin{array}{c}\text { Nama } \\
\text { Karya } \\
\text { wan }\end{array}$ & PTKP & Gaji Pokok & $\begin{array}{c}\text { Tunjangan } \\
\text { lain lain }\end{array}$ & $\begin{array}{c}\text { Tunjangan } \\
\text { Pph } 21\end{array}$ & \begin{tabular}{|c|} 
Tantiem, \\
Bonus, \\
GratifikTHR \\
yang \\
sifatnya \\
tidak tetap \\
\end{tabular} & $\begin{array}{c}\text { Ph. Bruto } \\
\text { Setahun }\end{array}$ & Biaya jabatan & $\begin{array}{l}\text { Ph.netto } \\
\text { Setahun }\end{array}$ & PTKP & PKP & $\begin{array}{c}\text { PPh21 di gross up } \\
\text { dibulatkan }\end{array}$ \\
\hline 1 & Tn.si & $\mathrm{TK} / 0$ & 44.000 .000 & 2.274 .684 & & & 46.274 .684 & 2.313 .734 & 43.960 .950 & 54.000 .000 & & \\
\hline 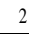 & Tn.wn & $\mathrm{TK} / 0$ & 72.000 .000 & 2.274 .684 & 1.046 .579 & 3.500 .000 & 78.821 .263 & 3.941 .063 & 74.880 .200 & 54.000 .000 & 20.879 .250 & 1.046 .579 \\
\hline & Ny.ap & $\mathrm{TK} / 0$ & 72.000 .000 & 2.274 .684 & 1.046 .579 & 3.500 .000 & 78.821 .263 & 3.941 .063 & 74.880 .200 & 54.000 .000 & 20.879 .250 & 1.046 .579 \\
\hline 4 & Tn.an & $\mathrm{TK} / 0$ & 72.000 .000 & 2.274 .684 & 1.046 .579 & 3.500 .000 & 78.821 .263 & 3.941 .063 & 74.880 .200 & 54.000 .000 & 20.879 .250 & 1.046 .579 \\
\hline & Ny.mi & $\mathrm{TK} / 0$ & 119.000 .000 & 8.110 .210 & 18.313 .529 & 70.000 .000 & 215.423 .739 & 6.000 .000 & 209.423 .739 & 54.000 .000 & 155.423 .529 & 18.313 .529 \\
\hline 6 & Ny.dn & $\mathrm{TK} / 0$ & 24.000 .000 & 251.967 & - & & 24.251 .967 & 1.212 .598 & 23.039 .369 & 54.000 .000 & & \\
\hline & Tn.ar & $\mathrm{K} / 2$ & 14.000 .000 & & - & & 14.000 .000 & 700.000 & 13.300 .000 & 54.000 .000 & & \\
\hline 0 & Tn.md & $\mathrm{K} / 1$ & 14.000 .000 & & - & & 14.000 .000 & 700.000 & 13.300 .000 & 67.500 .000 & & \\
\hline 9 & Tn.yf & $\mathrm{TK} / 0$ & 14.000 .000 & & - & & 14.000 .000 & 700.000 & 13.300 .000 & 63.000 .000 & & \\
\hline 10 & Tn.sy & $\mathrm{TK} / 0$ & 14.000 .000 & & . & & 14.000 .000 & 700.000 & 13.300 .000 & 54.000 .000 & & \\
\hline \multirow[t]{2}{*}{11} & Tn.kih & $\mathrm{TK} / 0$ & 19.661 .722 & 311.755 & - & & 19.973 .477 & 998.674 & 18.974 .803 & 54.000 .000 & & \\
\hline & & Total & 478.661.722 & $\mid 17.772 .668$ & 21.453.266 & 80.500 .000 & $\mathbf{5 9 8 . 3 8 7 . 6 5 6}$ & 25.148 .196 & 573.239.461 & 616.500 .000 & 218.061.279 & 21.453.268 \\
\hline
\end{tabular}

Sumber: Data Internal Mjayahadi \& Co Tahun 2018 (diolah Oleh Penulis)

Dari Tabel IV.4 dapat dilihat bahwa perhitungan PPh 21 dari 11 karyawan tetap dengan menggunakan metode gross up dapat diperoleh pajak penghasilan bruto sebesar Rp. 598.387.656,- dengan rincian gaji pokok sebesar Rp. 478.661.722,- THR sebesar Rp.80.500.000,- , Tunjangan Lain lain sebesar Rp.17.772.668,- dan Tunjangan pajak sebesar Rp.21.453.266 ,-dan dikurangi biaya jabatan sebesar Rp.25.148.196, sehingga akan menghasilkan penghasilan Netto sebesar Rp. 573.239.461,- atas penghasilan netto tersebut dikurangi kembali dengan total penghasilan tidak kena pajak sebesar Rp. 616.500.000,sehingga akan menghasilkan penghasilan kena pajak sebesar Rp. 218.061.279,- kemudian dari masingmasing karyawan dihitung pajak penghasilan Pasal 21 yang sudah menggunakan metode gross up sebesar Rp.21.453.268,-. Berdasarkan perhitungan tunjangan pajak penghasilan pasal 21 atas karyawan tetap, maka dapat diketahui jumlah biaya Operasional menjadi bertambah, dan juga mengakibatkan laba bersih perusahaan berkurang hal ini sesuai dengan Pasal 6 ayat 1a UU No.36 Tahun 2008 tentang pajak 
penghasilan, dimana biaya tunjangan pajak penghasilan pasal 21 atas karyawan dapat dibiayakan (deductible) dan dapat mengurangi laba bersih akhir tahun.

Tabel IV.5 Analisis Perhitungan PPh Pasal 21 Pada Persek Mjayahadi \& Co Tahun 2018

\begin{tabular}{|c|c|c|c|}
\hline Keterangan & $\begin{array}{c}\text { Metode } \\
\text { Gross }\end{array}$ & Metode Net & $\begin{array}{c}\text { Metode } \\
\text { Gross Up }\end{array}$ \\
\hline Alt I & Alt II & Alt III \\
\hline Gaji setahun & 478.661 .722 & 478.661 .722 & 478.661 .722 \\
\hline THR & 80.500 .000 & 80.500 .000 & 80.500 .000 \\
\hline Tunj.lain lain & 17.772 .668 & 17.772 .668 & 17.772 .668 \\
\hline Tunj. Pajak & - & & 21.453 .266 \\
\hline Penghasilan bruto & 576.934 .390 & 576.934 .390 & 598.387 .656 \\
\hline B. jabatan & 24.991 .209 & 24.991 .209 & 25.148 .196 \\
\hline Penghasilan Netto & 551.943 .181 & 551.943 .181 & 573.239 .460 \\
\hline PTKP & 355.178 .181 & 355.178 .181 & 355.178 .181 \\
\hline PKP & 196.765 .000 & 196.765 .000 & 218.061 .279 \\
\hline PPh 21 setahun & 18.549 .250 & 18.549 .250 & 21.453 .266 \\
\hline Tunjangan pajak & - & - & 21.453 .266 \\
\hline $\begin{array}{l}\text { PPh 21 yang harus } \\
\text { disetor / dipotong } \\
\text { dari penghasilan }\end{array}$ & 18.549 .250 & 18.549 .250 & \\
\hline
\end{tabular}

\section{Sumber : Data diolah oleh penulis}

Dapat disimpulkan bahwa PPh 21 menggunakan metode gross Up sebesar Rp. 18.549.250,- , Menggunakan Metode Net Sebesar Rp.18.549.250 dan menggunakan metode gross up PPh 21nya sebesar Rp.21.453.266,-- sehingga dapat digunakan sebagai pengurangan biaya dalam laporan keuangan tahunan perusahaan. Selanjutnya alternative yang dapat memberikan penghematan pajak dari besarnya penghematan pajak yang dihasilkan.

Berikut penulis tampilkan gambaran alternative yang paling menguntungkan bagi perusahaan dan karyawan dalam penggunaan alternative kebijakan.

\section{Tabel IV.6 Take Home Pay (THP) Pada Persek Mjayahadi \& Co Tahun 2018}

\begin{tabular}{|c|c|c|c|}
\hline Uraian & $\begin{array}{c}\text { Ditanggung } \\
\text { Karyawan }\end{array}$ & $\begin{array}{c}\text { Ditanggung } \\
\text { Perusahaan } \\
\text { (Net Method) }\end{array}$ & $\begin{array}{c}\text { Ditunjang } \\
\text { Perusahaan } \\
\text { (Gross Up } \\
\text { Method) }\end{array}$ \\
\hline Gaji & 478.661 .722 & 478.661 .722 & Alt III \\
\hline THR & 80.500 .000 & 80.500 .000 & 80.500 .000 \\
\hline $\begin{array}{c}\text { Tunjangan } \\
\text { Lain-lain }\end{array}$ & 17.772 .668 & 17.772 .668 & 17.772 .688 \\
\hline $\begin{array}{c}\text { Tunjangan } \\
\text { Pajak }\end{array}$ & - & - & 21.453 .266 \\
\hline $\begin{array}{c}\text { Penghasilan } \\
\text { Bruto }\end{array}$ & 576.934 .390 & 576.934 .390 & 598.387 .656 \\
\hline PPh 21 & 18.549 .250 & - & 21.453 .266 \\
\hline $\begin{array}{c}\text { Total Take } \\
\text { Home Pay }\end{array}$ & 558.385 .140 & 576.934 .390 & 576.934 .390 \\
\hline
\end{tabular}

Sumber : data diolah oleh penulis

Bahwa penghasilan bruto menggunakan metode gross Up mengalami kenaikan yang semula Rp.576.934.390,- menjadi Rp.598.387.656,--karena adanya tunjangan pajak sebesar Rp. 21.453.266,-- maka take home pay yang didapat karyawan meningkat semula Rp. 558.385.140,- menjadi Rp.576.934.390 karena seolah-olah yang semula pajak yang dibayarkan oleh karyawan itu sendiri menjadi perusahaan yang membiayai. 
Tabel IV. 7 Perhitungan Laba rugi Persek Mjayahadi \& Co Untuk Tahun berakhir 31 Desember 2018

\begin{tabular}{|c|c|c|c|}
\hline Keterangan & $\begin{array}{c}\text { Ditanggung } \\
\text { karyawan (Gross } \\
\text { Method) }\end{array}$ & $\begin{array}{c}\text { Ditanggung } \\
\text { perusahaan (Net } \\
\text { Method) }\end{array}$ & $\begin{array}{c}\text { Ditunjang } \\
\text { Perusahaan } \\
\text { gross Up } \\
\text { Method } \\
\end{array}$ \\
\hline Pendapatan Jasa & 24.310 .850 .000 & 24.310 .850 .000 & 24.310 .850 .000 \\
\hline Biaya Project & 10.186 .152 .673 & 10.186 .152 .673 & 10.186 .152 .673 \\
\hline Laba Kotor Usaha & 14.124 .697 .327 & 14.124 .697 .327 & 14.124 .697 .327 \\
\hline \multicolumn{4}{|l|}{ Biaya operasional: } \\
\hline Biaya operasional & 3.143 .843 .074 & 3.143 .843 .074 & 3.143 .843 .074 \\
\hline Gaji /THR/Tunj.mkn & 576.934 .390 & 576.934 .390 & 576.934 .390 \\
\hline Tunj. PPh 21 & - & & 21.453 .266 \\
\hline Total Biaya Operasional & 3.720 .777 .464 & 3.720 .777 .464 & 3.742 .230 .730 \\
\hline Laba Operasional & 10.403 .919 .863 & 10.403 .919 .863 & 10.382 .466 .597 \\
\hline \multicolumn{4}{|l|}{ Pendapatan diluar usaha: } \\
\hline Pendapatan (Biaya Lainya) & 15.338 .610 & 15.338 .610 & 15.338 .610 \\
\hline Laba Bersih Sebelum Pajak & 10.419 .258 .473 & 10.419 .258 .473 & 10.397 .805 .207 \\
\hline Pajak Penghasilan Badan & 2.413 .042 .358 & 2.413 .042 .358 & 2.408 .208 .515 \\
\hline Laba bersih setelah pajak & 8.006 .216 .115 & 8.006 .216 .115 & 7.989.596.692 \\
\hline \multicolumn{4}{|l|}{ Kredit Pajak } \\
\hline PPH Pasal 23 & 476.817 .000 & 476.817 .000 & 476.817 .000 \\
\hline PPh Pasal 25 & 1.152 .830 .727 & 1.152 .830 .727 & 1.152 .830 .727 \\
\hline Total Kredit Pajak & 1.629 .647 .727 & 1.629 .647 .727 & 1.629 .647 .727 \\
\hline Kurang (Lebih) Bayar & 6.376 .568 .388 & 6.376 .568 .388 & 6.359.948.965 \\
\hline
\end{tabular}

Sumber :data diolah oleh penulis

Dari tabel IV.7 dapat terlihat perbandingan antara total beban pajak perusahaan dari pajak penghasilan pasal 21 dan pajak penghasilan badan setelah perencanaan pajak . dengan penggunaan metode pemotongan pajak penghasilan pasal 21 ditanggung oleh karyawan, pajak penghasilan badan sebesar Rp. 2.413.042.358,dengan penggunaan metode pemotongan Pajak penghasilan pasal 21 ditanggung perusahaan Pajak Penghasilan Badannya sebesar Rp.2.413.042.358,- sedangkan Menggunakan Metode pemotongan PPh 21 ditunjang Perusahaan maka pajak penghasilan badan sebesar Rp. 2.408.208.515,- kemudian berikut penulis tampilkan perbandingan dari hasil perhitungan dengan alternative metode pemotongan pajak penghasilan pasal 21 yang dilakukan oleh Persek Mjayahadi \& Co untuk menganalisis seberapa besar dampak perencanaan pajak atas pajak penghasilan pasal 21 tersebut pada pencapaian penghematan pajak untuk keuntungan perusahaan.

Tabel IV.8 Analisis Perhitungan Laba Rugi Pada Persek Mjayahadi \& Co Tahun 2018

\begin{tabular}{|c|c|c|c|}
\hline Keterangan & $\begin{array}{l}\text { menggunakan } \\
\text { metode gross }\end{array}$ & $\begin{array}{c}\text { menggunakan } \\
\text { metode } N e t\end{array}$ & $\begin{array}{c}\text { menggunakan } \\
\text { metode Gross Up }\end{array}$ \\
\hline & Alt I & Alt.II & Alt. III \\
\hline $\begin{array}{l}\text { PPh } 21 \text { (sebagai } \\
\text { tunjangan pajak) }\end{array}$ & & & 21.453 .266 \\
\hline PPh Badan & 2.413 .042 .358 & 2.413 .042 .358 & 2.408 .208 .515 \\
\hline $\begin{array}{l}\text { Total Pajak ( beban } \\
\text { perusahaan ) }\end{array}$ & 2.413 .042 .358 & 2.413 .042 .358 & 2.429 .661 .781 \\
\hline $\begin{array}{c}\text { PPh } 21 \text { (Beban } \\
\text { Perusahaan bukan } \\
\text { sebagai Tunjangan } \\
\text { Pajak) }\end{array}$ & & 18.549 .250 & \\
\hline $\begin{array}{l}\text { PPh } 21 \text { ( beban } \\
\text { pegawai }\end{array}$ & 18.549 .250 & & \\
\hline Total Pajak & 2.431 .591 .608 & 2.431 .591 .608 & 2.429 .661 .781 \\
\hline $\begin{array}{c}\text { Laba bersih setelah } \\
\text { pajak }\end{array}$ & 8.006 .216 .115 & 8.006 .216 .115 & 7.989 .596 .692 \\
\hline $\begin{array}{l}\text {-/-: PPh } 21 \text { (non } \\
\text { deductible) }\end{array}$ & & 18.549 .250 & \\
\hline $\begin{array}{c}\text {-/-: PPh } 21 \text { ( beban } \\
\text { pegawai non } \\
\text { deductible) }\end{array}$ & 18.549 .250 & & \\
\hline $\begin{array}{c}\text { Laba bersih setelah } \\
\text { Pajak dan beban non } \\
\text { deductible }\end{array}$ & 7.987 .666 .865 & 7.987 .666 .865 & 7.989 .596 .692 \\
\hline
\end{tabular}

Sumber : data diolah oleh Penulis 
Penjelasan :

a. Secara total pajak bila diperhitungkan atas pajak penghasilan yang dibebankan kepada karyawan( Alt I) dan ditanggung oleh perusahaan (Alt II), maka alternative III yakni pajak penghasilan pasal 21 dengan menggunakan metode ditunjang Perusahaan memberikan penghematan pajak bagi perusahaan maupun karyawan karena total pajaknya lebih kecil dengan alternative yang saat ini digunakan oleh perusahaan yaitu PPh pasal 21 ditanggung karyawan dengan selisih nilai sebesar Rp. 1.929.827,-- yang didapatkan dari total pajak dengan metode ditanggung karyawan(metode Gross) Yaitu sebesar Rp. 2.431.591.608 ',- dikurangi dengan total pajak dengan menggunakan metode gross up yaitu sebesar Rp. 2.429.661.781

b. Bila diperhitungkan beban pajak penghasilan pasal 21 yang menjadi tanggungan karyawan (alternative I ) yang saat ini diterapkan perusahaan dengan (alternative III ) yakni metode gross up yang dtunjang perusahaan memberikan laba bersih setelah pajak dikurangi beban non deductible yang lebih besar bagi perusahaan dengan selisih Rp. 1.929.827,-dari laba bersih sebelum diterapkan metode Gross Up sebesar Rp 7.987.666.865,-- setelah diterapkannya metode gross Up menjadi Rp 7.989.596.692 ,- maka besarnya selisih tersebut jumlahnya sama besar dengan besarnya efisiensi pajak.

\section{KESIMPULAN}

1. Mjayahadi \& Co dalam melakukan perpajakannya masih menggunakan Gross Method dalam perhitungan PPh Pasal 21, sebenarnya Mjayahadi dapat mengefesiensikan pajak penghasilan $\mathrm{PPh} 21$ dengan menggunakan Gross Up Method dalam perhitungan PPh 21. Perencanaan pajak dalam perhitungan PPh 21 dengan menggunakan Groos Method dan Gross Up Method tidak bertentangan dengan ketentuan perpajakan.

2. Dampak Perubahan yang dapat dirasakan dari perencanaan pajak menggunakan Gross method, Net Method dan Gross Up Method pada Pajak penghasilan PPh 21 adalah. Yang pertama dengan menggunakan Gross Method, dampak bagi pegawai Take Home pay yang didapat tidak besar, hal ini karna PPh 21 dipotong dari penghasilan, sehingga beban PPh 21 tersebut mengurangi penghasilan Pegawai. Dengan menggunakan Net Method ini tidak merugikan Pegawai, karena penghasilan yang didapat tidak dikurangi dengan $\mathrm{PPh} 21$, tetapi merugikan perusahaan karena perusahaan yang menanggung biaya atas PPh 21 tersebut, dan tidak dapat dibebankan dari penghasilan bruto perusahaan karena merupakan biaya Non-deductible. Sedangkan dengan menggunakan Gross Up Method akan membuat beban pajak perusahan menurun dan take home pay karyawan mengalami kenaikkan. Bila diperhitungkan, pajak penghasilan badan selisih, dari total pajak dan laba bersih setelah pajak dikurangi beban non deductible sebelum menggunakan metode gross up dengan setelah diterapkannya metode gross up sebesar Rp. 1.929.827 yang jumlahnya sama besar dengan efisiensi pajak.

3. Hambatan yang terjadi dalam perencanaan pajak Penghasilan PPh 21 sebagai upaya untuk meningkatkan efesiensi beban pajak pada persek Mjayahadi \& Co diantaranya, dalam mensinkronisasikan regulasi perusahan, karena terkadang regulasi perusahan tidak sejalan dengan rencana tax planning. Yang kedua adalah salah dalam menafsirkan undang undang yang ada, kemudian pengetahuan perpajakan masih kurang dalam melakukan perencanaan pajak. Adapun upaya yang telah dilakukan dalam perencanaan pajak Penghasilan PPh 21 yaitu untuk meningkatkan efesiensi beban pajak, persek Mjayahadi \& Co melakukan pengawasan dalam perencanaan pajaknya untuk mengatasi hambatan yang terjadi, mengkaji ulang tax planning yang telah dilakukannya apabila ada perubahan - perubahan peraturan mengenai perpajakan yang berpengaruh dalam perencanaan pajak yang dilakukan, serta memberikan pelatihan pelatihan kepada karyawan yang menangani pajak perusahaan.

\section{REFERENSI}

\section{Buku-buku:}

Kasiram, P. (2010). Metodologi Penelitian Kualitatif-Kuantitatif. Malang: UIN-Maliki Press.

Mansury, R. (1996). Panduan Konsep Utama Pajak Penghasilan Indonesia Jilid 2. Jakarta: Bina Rena Pariwara.

Mardiasmo. (2016). Perpajakan Edisi Revisi Tahun 2016. Yogyakarta: Andi.

Moleong, L. J. (2016). Metodologi Penelitian Kualitatif Edisi Revisi. Bandung:: PT. Remaja Rosdakarya.

Mulyadi. (2016). Sistem Informasi Akuntansi. Jakarta: Salemba Empat.

Nazir.Mohammad, P. (2011). Metode Penelitian. Jakarta : Ghalia Indonesia.

Nordiawan, Deddi,\&Hertianti, A. (2014). Akuntansi Sektor Publik. Jakarta: Salemba Empat

Neuman, W. L. (2006). Social Research Methods Qualitative and Quantitative Approach 6Th. Boston: Allyn and Bacon. 
Neuman, W. L. (2011). Social Research Methods Qualitative and Quantitative Approach 7Th. Boston: Person Education INC.

Pasolong, H. (2012, ). Metode Penelitian Administrasi Publik,. Bandung: Alfabeta.

Pohan, C. A. (2014). Pengantar perpajakan. Jakarta: Mitra Wacana Media.

Pohan, C. A. (2016). Manajemen Perpajakan. Jakarta: Gramedia Pustaka Utama.

Resmi, S. ( 2017). Perpajakan Teori dan Kasus (Edisi ke 10 Buku 1). Jakarta: : Salemba Empat.

Syafiie, I. K. (2015). Ilmu Administrasi. Yogyakarta: Pustaka Pelajar.

\section{Jurnal}

Daengs, A. (GS 2018). Tax Planning Implementation on Income Tax, Article 23 as A Legal Effort To

Minimize Tax Expense Payable,Jurnal Terapan Manajemen dan bisnis (vol 4. No 1).

https://journal.stkipsingkawang.ac.id/index.php/JTMB/article/view/483

Nabilah, N. N. (2016). Analisis Penerapan Perencanaan Pajak Pph 21 Sebagai Upaya Penghematan Beban Pajak Penghasilan Badan (Studi Kasus Pada Pt Z, jurnal Perpajakan ( Vol 8, No 1 ).

http://perpajakan.studentjournal.ub.ac.id/index.php/article/view/242

Vridag, R. V. (2015). ANALISIS PERBANDINGAN PENGGUNAAN METODE NET BASIS DAN METODE. jurnal EMBA, 306-314.

https://ejournal.unsrat.ac.id/index.php/emba/article/view/10897/10487

Chaezahranni, S. (2016). Penerapan Perencanaan Pajak (Tax Planning) atas Pemotongan Pajak.

https://media.neliti.com/media/publications/172182-ID-penerapan-perencanaan-pajak-tax-planning.pdf

Setiawan, H. A. (2017). Penerapan Metode Gross Up Atas Perhitungan PPh Pasal 21 Sebagai Alternatif Efesiensi Pajak. Ilmu dan riset Akutansi, 1-22. (Vol 6 No 6)

https://docplayer.info/57980308-Penerapan-metode-gross-up-atas-perhitungan-pph-pasal-21-sebagai-

alternatif-efisiensi-pajak.html

Pramono, S. (2016). Analisis perencanaan pajak PPh 21 Sebagai Upaya Untuk Mengoptimalkan Pemenuhan Kewajiban Pajak Penghasilan Pada yayasan bala keselamatan rumah sakit william both surabaya. (Vol 2 No 4)

http://fe.ubhara.ac.id/ojs/index.php/equity/article/view/238

\section{Perundang-undangan}

Undang-Undang Republik Indonesia Nomor 28 Tahun 2007 Tentang Perubahan Ketiga Atas Undang-

Undang Nomor 6 Tahun 1983 Tentang Ketentuan Umum Dan Tata Cara Perpajakan

Undang-Undang Nomor 36 Tahun 2008 Tentang Perubahan Keempat Atas Undang-Undang Nomor 7 Tahun 1983 Tentang Pajak Penghasilan

Undang-Undang Republik Indonesia Nomor 36 Tahun 2008 tentang Perubahan Keempat atas Undang-

Undang Nomor 7 Tahun 1984 tentang Pajak Penghasilan. 